JURNAI PANGKAJA PROGRAM PASCASARJANA UNIVERSITAS HINDU NEGERI I GUSTI BAGUS SUGRIWA DENPASAR
Vol.24, No. 1, Maret 2021

ISSN : 1412-7474 (Cetak)

IS SN : 2623-2510 (Online)

http://ejournal.ihdn.ac.id

\title{
KAJIAN TEO-SEKSUAL LONTAR RAHASYA SANGGAMA
}

\author{
Kadek Agus Wardana $^{1}$; I Ketut Donder ${ }^{2}$; I Gede Suwantana ${ }^{3}$ \\ Pogram Studi Brahma Widya, Program Pascasarjana, \\ Universitas Hindu Negeri I Gusti Bagus Sugriwa Denpasar \\ Email: agoes.wardana89@gmail.com ${ }^{1}$; donderjyothi@gmail.com² \\ Diterima tanggal 17 Januari 2021, diseleksi tanggal 29 Januari 2021, \\ dan disetujui tanggal 10 Februari 2021
}

\begin{abstract}
Sex is an inseparable part of human life. Even so, sex has not been fully understood because more people view sex as something sacred and secret so that sex is only interpreted as a taboo or prohibition to be taught. That is the way of the past view of sex, but lately many parties view sex education is important. Because it is very warmly discussed later. During this time sexuality is often understood as something taboo to talk about especially if it is associated with religion. Of course there are many who refuse to discuss porn in a religious context. Hinduism provides a different view of sexuality. In Hinduism sexuality is seen as a sacred thing in human life because it is implicitly contained in the purusārtha chess teachings, namely dharma, artha, kama, and moksa. One of the goals of human life is the fulfillment of lust or desire (kama) which encourages people to do something that makes people excited in this life. Sex which is equated with kama in Sanskrit and Old Javanese has a place in human life. It cannot be eliminated just behind the current time, because it continues to flow as an instrument of strength to obtain the highest virtue. "People without kama will never want artha and people without kama will never want dharma either. Enjoying spirituality in sexuality activities for Hindus especially Hindus in Bali and Indonesia can be found in the Rahasya Sanggama lontar text. The Balinese have had the Rahasya Sanggama ejection as a sacred guideline in sexual activity, if the guideline is implemented properly, then there should be very few sexual cases in the Balinese environment.
\end{abstract}

Keywords: Rahasya Sanggama Text, Teo-Sexual Study

\begin{abstract}
ABSTRAK
Seks merupakan bagian yang tidak terpisahkan dengan kehidupan manusia. Walaupun demikian seks belum dipahami secara utuh disebabkan lebih banyak orang memandang seks sebagai sesuatu yang sacral dan rahasia sehingga seks hanya dimaknai sebagai pantangan atau larangan untuk diajarkan. Itu adalah cara pandang masa lalu terhadap seks, namun belakangan banyak pihak memandang pendidikan seks merupakan hal yang penting. Karena itu sangat hangat didiskusikan belakangan. Selama ini seksualitas seringkali dipahami sebagai
\end{abstract}


sesuatu yang tabu untuk dibicarakan apalagi jika itu dikaitkan dengan agama. Sudah barang tentu banyak yang menolak kalau pembicaraan porno dilakukan dalam konteks beragama. Hindu memberikan pandangan yang berbeda tentang seksualitas. Dalam Hindu seksualitas dipandang sebagai hal yang sakral dalam kehidupan manusia sebab secara implisit termuat dalam ajaran catur purusārtha, yaitu dharma, artha, kama, dan moksa. Salah satu tujuan hidup manusia adalah terpenuhinya nafsu atau keinginan (kama) yang mendorong orang berbuat sesuatu yang membuat orang bergairah dalam hidup ini. Seks yang disepadankan dengan kama dalam bahasa Sanskerta dan bahasa Jawa Kuno mempunyai tempat yang dalam kehidupan manusia. Ia tidak bisa dihilangkan begitu saja dibalik waktu yang tengah berjalan, karena ia mengalir terus sebagai alat kekuatan untuk mendapatkan kebajikan tertinggi. "Orang tanpa memiliki kama tidak akan pernah menginginkan artha dan orang tanpa memiliki kama, juga tak akan pernah menginginkan dharma. Menikmati spiritualitas dalam aktivitas seksualitas bagi umat Hindu khususnya umat Hindu di Bali dan Indonesia dapat ditemukan dalam teks lontar Rahasya Sanggama. Masyarakat Bali telah memiliki lontar Rahasya Sanggama sebagai pedoman suci dalam melakukan aktivitas seksual, jika pedoman itu diimplementasikan sebagaimana mestinya, maka seharusnya sangat sedikit kasuskasus seksual di lingkungan masyarakat Bali.

Kata Kunci: Teks Rahasya Sanggama, Kajian Teo-Seksual

\section{PENDAHULUAN}

Sejak berpuluh-puluh tahun seks di Indonesia dipandang sebagai sesuatu yang tabu untuk dibicarakan di depan umum bahkan sangat dipantangkan pada kalangan anak-anak usia SD, SMP, dan SMA. Sehingga seks hanya dipelajari bagi para mahasiswa kedokteran dan lebih spesifik lagi oleh para mahasiswa jurusan seksologi. Namun belakangan ini, paling tidak sejak tahun 1990-an, dengan menyaksikan semakin banyak tragedi-tragedi seksual terjadi pada para remaja, maka banyak pakar di bidang pendidikan memandang bahwa pendidikan seks layak diajarkan kepada para siswa-siswi dan para remaja dan para mahasiswa.

Sejak itu masalah seks sedikit demi sedikit mulai tidak ditabukan lagi bagi anak SD, SMP, dan SMA bahkan ada rencana pendidikan seks akan dimasukkan dalam kurikulum dan diajarkan sejak SD. Walaupun rencana itu sampai sekarang belum direalisasikan atau diajarkan menjadi mata pelajaran seksologikarena kalangan agamawan masih mempertimbangkan secara matang. Sebab secara religius seks adalah dalam rangka reproduksi atau setidaknya dipandang bahwa hubungan seks dipandang sebagai kewajiban suci untuk saling membahagiaan antara suami-istri. Tetapi bagi anak muda (pelajar dan mahasiswa) yang berada pada usia pancaroba yang belum kawin secara resmi, maka keinginan untuk merasakan hubungan seks seperti yang didengar melalui lingkungan apalagi lingkungan pendidikan pasti meletup-letup dan hubungan seks bebas kalangan remaja akan dianggap sebagai hal yang wajar sebagaimana disinyalir oleh berbagai media cetak, majalah, koran dan elektronika lainnya serta hasil penelitian tesis. Hal ini suatu kekhawatiran dari para pemuka agama yang beralasan, inilah fenomena, inilah isu. Jika dibandingkan dengan pandangan Hindu, sikap dan pandangan para pakar belakangan yangmenganggap bahwa seks perlu diajarkan sejak dini, maka ini sangat ketinggalan. Sebab, sesungguhnya dalam Hindu baik di Indonesia apalagi di India perihal seks bukan suatu yang dipantangkan, bahkan seks di India 
diwacanakan dan diwujudkan sebagai suatu hal yang bersifat suci. Seks dalam Hindu bahkan sebagai suatu yang berhubungan dengan Tuhan, karena seks dan hubungan seks dilukisan dalam bentuk-bentuk pahatan dalam candi-candi Hindu sebagai simbol. Sebagaimana bentuk Lingga-Yoni adalah simbol dari sifat Tuhan sesuai dengan Teologi Nir-Saguna Brahman, artinya bahwa Tuhan yang tidak bisa dibayangkan (acintya) sama sekali, tetapi boleh dibuatkan simbol (nyasa) agar dapat dibayangkan. Tetapi, walaupun dibuatkan simbol, namun Tuhan tetap tidak dapat dibayangkan, fungsi simbol benar-benar sebagai alat atau sarana untuk memusatkan pikiran.

Lingga-Yoni berubah bentuknya dalam Teologi Saguna Brahma yang digambarkan dengan segala sesuatu yang bersifat biner berfungsi sebagai simbol yang hendak menggambarkan sifat Tuhan yang berpasangan atau rwabhineda melalui sesuatu yang mudah dibayangkan seperti: Shiva-Parvati; Ardhanaresvari' Purusha-Pradana atau Purusha-Prakriti, Prthivi-Akasha, dll., yang pada intinya bertujuan sebagai simbol dari sifat Tuhan yang kebapakan dan keibuan. Simbolisasi seks baik dalam arti sebagai perbedaan jenis kelamin ataupun sebagai hubungan kelamin telah popular dipahami oleh umat Hindu sejak masa lampau, sebab simbol seks bukan hanya dikenal dalam teks-teks yang suci dan disembunyikan tetapi simbol seks disimbolkan sebagai suci lingga-yoni atau simbol maskulin dan feminim. Simbol-simbol seks di lingkungan Hindu bukan hanya popular di India tetapi juga sangat dikenal sangat familiar di Nusantara sebagaimana terlihat di lingkungan Candi Cetho, Jawa Tengah.

Seks merupakan bagian yang tidak terpisahkan dengan kehidupan manusia. Walaupun demikian seks belum dipahami secara utuh disebabkan lebih banyak orang memandang seks sebagai sesuatu yang sakral dan rahasia sehingga seks hanya dimaknai sebagai pantangan atau larangan untuk diajarkan. Itu adalah cara pandang masa lalu terhadap seks, namun belakangan banyak pihak memandang pendidikan seks merupakan hal yang penting. Karena itu sangat hangat didiskusikan belakangan.

Seksualitas adalah seseorang merasa tentang dirinya dan mengkomunikasi yang dilakukan perasaan tersebut kepada orang lain melalui tindakan yang dilakukannya seperti sentuhan, pelukan, ataupun perilaku yang lebih halus seperti isyarat gerak tubuh, cara berpakaian, dan perbendaharaan kata, termasuk pikiran, pengalaman, nilai, fantasi, emosi. Selama ini seksualitas seringkali dipahami sebagai sesuatu yang tabu untuk dibicarakan apalagi jika itu dikaitkan dengan agama. Sudah barang tentu banyak yang menolak kalau pembicaraan porno dilakukan dalam konteks beragama (Tim, 1995:893).

Sebagaimana telah disinggung sedikit di atas, bahwa Hindu memberikan pandangan yang berbeda tentang seksualitas. Dalam Hindu seksualitas dipandang sebagai hal yang sakral dalam kehidupan manusia sebab secara implisit termuat dalam ajaran catur purusārtha, yaitu dharma, artha, kama, dan moksa. Salah satu tujuan hidup manusia adalah terpenuhinya nafsu atau keinginan (kama) yang mendorong orang berbuat sesuatu yang membuat orang bergairah dalam hidup ini. Hal penting yang dapat dipetik dari tema seks dalam Hindu adalah bahwa bagi manusia, seks, hubungan seks, dan penyatuan seks, merupakan persembahan di dalam lapangan kegiatan yang suci. Oleh karena itu, suatu pengalaman seksual yang membahagiakan akan menjadi sumber tanggung jawab yang besar untuk mengembangkan sikap sosial, kedermawanan, kesadaran akan keindahan dan 
kualitas spiritualitas. Seks sesuai konteks ini dirasakan tidak sekadar sebagai media reproduksi, tetapi juga sebagai media pembentukan kelompok-kelompok dalam masyarakat, mengandung nilai kultural dan religius, karena dari sana tercipta keturunan-keturunan manusia sebagai mahluk ciptaan Tuhan. Pengetahuan seks secara benar layak diberikan kepada semua orang dan semua tingkatan. Namun kedalaman dan prakteknya seharusnya berbeda. Bagi pasangan suami istri atau para Grhasthin, untuk zaman sekarang seks bukan lagi merupakan persoalan domestik yang hanya dibahas oleh pasangan suami istri di dalam kamar tidur, namun telah menjadi persoalan banyak pihak dan dibicarakan dimana saja dan sudah menjadi persoalan publik. Bahkan dalam pandangan spiritual Tantra, seks dipandang sebagai salah satu dari kegiatan paling suci manusia yang mengharuskan doa-doa ikut andil memberi sentuhan suci pada desahan nafas dua orang suami istri yang memohon pada Tuhannya akan kelahiran seorang anak suputra (mulia) ataupun anugrah kenikmatan tanpa batas dalam ritus senggamanya yang suci. Sehingga seks yang dilakukan dalam suatu pernikahan Hindu tidak hanya sebagai pelampiasan nafsu birahi, melainkan sebagai suatu kegiatan suci yang berlandaskan dharma. Agama Hindu sebagaimana juga agama-agama lainnya melarang perbuatan zina (Skt., sānkkarika) merupakan hubungan seks yang dilakukan tidak dengan pasangan suami-istri yang sah.

Pasangan suami istri juga harus saling melengkapi dalam suatu hubungan sehingga mampu menjaga kelanggengan hubungan suami istri. Kepuasan pasangan dalam hubungan seks menjadi hal paling penting yang harus diingat. Hendaknya suami dan istri sudah mengetahui cara memuaskan pasangannya masing-masing dengan teknik-teknik maupun pengetahuan tentang tata cara melakukan hubungan seks yang dianjurkan dalam teks-teks Kama Tattwa diatas. Dan hendaknya hubungan tersebut dilakukan dengan pemilihan hari yang baik sehingga hasil yang diinginkan dari hubungan seks tersebut yaitu anak yangsuputra dapat terwujud.

Seks menjadi parameter dari suatu keluarga dan pemahaman tentang tata cara seks sangat diperlukan. Seksual merupakan salah satu dari tujuan wiwaha yang disebut "Rati" artinya menikmati kehidupan seksual dan indra lainya. Di kalangan Grhasthin diantara kebutuhan akan sandang, pangan, dan papan, seks adalah kebutuhan biologis yang mesti mendapat perhatian. Bahkan dalam buku "Malam Pengantin" dikatakan bahwa pengetahuan seks bagi orang dewasa merupakan senjata. Aktivitas seks (Sex Act) melibatkan kenikmatan syaraf-syaraf, sering kali hanya terfokus pada organ-organ tubuh yang dikenal dengan alat kelamin (Genetalia), yang sebetulnya melibatkan pula bagian tubuh lainya seperti: tangan, mulut, dada, telinga yang secara sosial budaya pemahamanya dikenal dengan istilah seksualitas.

Kesenangan seks yang dilakukan tidak akan berdampak secara spiritual tanpa ada kemauan untuk menggali kedalam khasanah seks sebagai hal yang spiritual. Ini diibaratkan sebagai seorang pengendara kereta agung yang lengkap dengan bala tentaranya, tetapi dirinya sendiri tidak memiliki lengan untuk berperang. Betapapun kemampuan yang dimiliki dalam perang namun tanpa lengan tidaklah mungkin untuk menangkal serangan musuh serta balik menyerangnya. Seks tidak hanya dapat dilakukan dengan berhubungan badan dan kepuasan semata, akan tetapi seks bila diikuti dengan spiritual yang mumpuni, maka aktivitas seksual seperti itu dapat mengantarkan orang pada kekebahagiaan tertinggi. Uraian di atas sangat sulit dipahami oleh orang yang masih terbelenggu oleh etika formalitas yang bersifat 
ketertiban sosial. Namun uraian di atas dapat dipahami oleh orang yang benar-benar melihat seks sebagai aktivitas religius. Sesuai paparan di atas, maka harapan untuk dapat menikmati spiritualitas dalam aktivitas seksualitas bagi umat Hindu khususnya umat Hindu di Bali dan Indonesia dapat ditemukan dalam teks lontar Rahasya Sanggama. Hal tersebut dapat penulis ketahui melalui membaca secara selintas lontar Rahasya Sanggama terdapat uraian tentang asuransi dan garansi nikmat spiritual yang akan diperoleh melalui hubungan seks secara benar.

LontarRahasya Sanggama menguraikan cara-cara membangun hubungan pasangan suami istri sesuai kaidah-kaidah atau norma-norma yang dianjurkanyang bertujuan untuk mencapai tujuan hidup mokshartham jagadhita ya ca iti dharma. LontarRahasya Sanggama ini sesungguhnya telah lama dimiliki oleh sebagian masyarakat umat Hindu Bali, walaupun kepemilikannya bersifat secara sembunyisembunyi dan dipraktekan. Karena itu jika Lontar Rahasya Sanggama ini dapat disebarkan secara terprogram kepada masyarakat yang sudah berkeluarga sebagai pedoman suci dalam melakukan aktivitas seksual sebagaimana mestinya, maka seharusnya sangat sedikit kasus-kasus seksual di lingkungan masyarakat Bali, khususnya kasus-kasus terkait keretakan hubungan rumah-tangga. Tetapi, realitasnya pada umumnya masyarakat Bali, seks itu lebih cenderung digunakan sebagai ajang pemuasan birahi, sehingga tidak sesuai dengan ajaran teks Rahasya Sanggama. Inilah gap atau distansi antara da solen (konsep, teori, teks) dan da sein (dalam praktik, realitas, atau kenyataan).

Metode yang dimaksud adalah cabang ilmu yang mempelajari cara-cara melakukan pengamatan yaitu meliputi kegiatan-kegiatan mencari, mencatat, merumuskan, menganalisa sampai menyusun laporan berdasarkan fakta-fakta atau gejala-gejala secara ilmiah. Melaksanakan suatu penelitian untuk mendapatkan data yang valid dan konsisten, maka diperlukan adanya metode sehingga hasil yang diperoleh dapat dipertanggung jawabkan secara ilmiah (Narbuko, 2003: 03). Penelitian ini tergolong ke dalam penelitian kualitatif, bahwa dalam tradisi penelitian kualitatif, proses penelitian dan ilmu pengetahuan tidak sesederhana yang terjadi pada penelitian kuantitatif, karena sebelum hasil-hasil penelitian kualitatif memberi sumbangan kepada ilmu pengetahuan, tahapan penelitian kualitatif melampaui berbagai tahapan berpikir kritis-ilmiah, maka seorang peneliti memulai berpikir secara induktif, yaitu menangkap berbagai fakta atau fenomena sosial melalui pengamatan di lapangan kemudian menganalisisnya dan kemudian berupaya melakukan teorisasi berdasarkan yang diamati. Pendekatan penilitian ini adalah pendekatan teologi, khususnya teologi Hindu, disebut sebagai pendekatan teologi Hindu karena kerangka berpikir teologisnya menggunakan cara pandang teologis sebagaimana pandangan Hindu yang pada umumnya dikenal memiliki dua macam teologi, yaitu teologi Nirguna Brahman dan Saguna Brahman. Penelitian ini dapat dinyatakan lebih cenderung pada teologi Saguna Brahman yang memandang bahwa Tuhan boleh dibayangkan sebagai sesuatu dengan sifat-sifat tertentu. Sesuai dengan isi penelitian Lontar Rahasya Sanggama, Tuhan dianggap bermanifestasi sebagai sifat maskulin (purusha, atau laki-laki) dan feminim (prakirthi, pradana atau perempuan). Hanya dalam teologi Hindu mengenal konsep bahwa Tuhan bermanifestasi. Karena itu penelitian ini disebut penelitian yang menggunakan pendekatan teologi Hindu. 


\section{PEMBAHASAN}

Tersedianya naskah-naskah lontar seks sejak dahulu di Bali, membuat Bali memiliki puluhan teks yang khusus membahas masalah kama, yang memang penyajiannya bernafaskan ajaran Hindu sehingga dapat dinamanya sebagai naskah lontar seks Hindu. Ketersediaannya naskah lontar kama dalam kasusastraan Bali menunjukkan adanya bukti bahwa beratus tahun yang lalu telah ada penelitian tradisional atau kajian mendalam secara tradisional terhadap permasalahan seks (kama). Hal ini juga mengindikasikan bahwa seks dalam budaya Bali bukan ajaran yang ditabukan atau suatu yang harus ditutup-tutupi sepanjang berada pada jalur yang benar (dharma).

Penjelasan teks LontarRahasya Sanggama membahas tentang cara berhubungan sanggama yang dilakukan guna mencari kenikmatan seksual sebagai berikut: (1) angguliprawesa (dengan memasukkan jari tangan ke liang vagina), (2) Purusaprawesa (dengan memasukkan zakar/penis ke liang vagina), dan (3) Jihwaprawesa (dengan menggunakan/memasukkan lidah ke liang vagina). Dua di antara ketiga cara tersebebut tampaknya lebih bersifat sebagai pedoman suami dalam upaya memberi kepuasan hubungan seksual pada istrinya. Keduanya itu, yaitu nomor (1) angguliprawesa dan (3) jihwaprawesa adalah hubungan seksual yang bersifat horizontal atau keduniawian. Cara nomor (1) dan (3) lebih condong sebagai upaya untuk memberi kepuasan istri. Sedangkan yang ke (2) Purusaprawesa merupakan ranah natural spiritual baik dalam hubungannya dengan keinginan membuat keturunan maupun simbol lingga-yoni atau ang-ah, prithiakasa, yang melibatkan kenikmatan keduanya.

\subsection{Eksploitasi Hubungan Seks Sumber Kesalahpahaman}

Nafsu terhadap lawan jenis atau nafsu seks dianggap sebagai kebutuhan pokok oleh para ahli. Dinyatakan bahwa pasangan suami-istri yang kurang melakukan hubungan seks akan kurang sehat, sebaliknya pasangan suami-istri yang sering melakukan hubungan seksual akan memiliki kesehtan yang baik. Pustaka Kama Sutra sesungguhnya telah memaparkan bahwa seks adalah realitas seks kehidupan dan sebagai sesuatu yang alamiah dan bersifat suci, Sebab keberadaan pria dan wanita di dunia adalah dalam rangka untuk mewujudkan cita-cita gagasan kepriaan dan kewanitaan yang awalnya adalah spirit Dewa Kamajaya dan Dewa Kamaratih yang ada di alam metafisik dan kemudian bertransformasi ke dalam alam fisik menjadi manusia. Karena itu baik dari pihak pria maupun wanita yang jatuh cinta ingin menyetubuhi atau disetubuhi adalah suatu hal yang alamiah.

Pustaka Veda Smrti memberikan petunjuk seorang wanita atau istri agar sedikit demi sedikit mengurangi nafsu birahinya untuk berhubungan seksual agar seorang istri yang menjadi inti setiap upacara dalam rumah tangga pikirannya selalu suci, itulah sebabnya pustaka Manava Dharmasastra V.157 menyatakan: "Berdasar keinginannya sendiri hendaknya ia (seorang istri) memperlemah nafsu badannya, dengan hidup dari bunga-bunga suci, ubi-ubian dan buah-buahan, tetapi ia tidak boleh menyebut nama laki-laki lain setelah suaminya meninggal".

Hubungan seksual betul-betul diatur sebagai swadharma suci antara suami dan istri yang mesti dilaksanakan sebagai wujud bhakti. Sedangkan yang dilarang bahkan dicela adalah melakukan hal-hal tindakan buruk bagi wanita adalah mengeksploitasi dirinya menjadi pelacur apalagi pelacur yang melayani seksual 
beberapa kali dalam satu kali persetubuhan. Karena itu pelacur dianggap perbuatan serendah-rendahnya perbuatan wanita, hal tersebut dapat dibaca pada sloka-sloka berikut:

Janganlah hendaknya ia menerima hadiah dari seorang raja yang bukan keturunan ksatriya, tidak pula dari para jagal, para pembuat minyak, dan tukang pungut pajak, tidak pula dari mereka yang hidup dari keuntungan memelihara pelacur (germo).

Manava Dharmasastra IV.84

Satu rumah pembuat minyak sama jeleknya dengan sepuluh rumah pembantaian, satu rumah minum sama jeleknya dengan sepuluh rumah pembuat minyak, satu rumah pelacuran sama jeleknya dengan sepuluh rumah minum, seorang raja yang tidak baik sama jeleknya dengan sepuluh tempat lacur.

\section{Manava Dharmasastra IV.85}

Berdasarkan uraian sloka-sloka di atas memberikan pengetahuan kepada kita bahwa menjadi pelacur dan aktivitas pelacuran itulah yang dianggap sebagai suatu yang tidak memahami hakikat suci seks karena itu dinyatakan tidak benar. Seks sebagai aktivitas religius sampai sekarang belum diajarkan secara resmi oleh sebuah lembaga keagamaan sebagai suatu pembelajaran formal atau resmi secara akademis.

Pihak agama selalu ketinggalan dengan sains dan teknologi karena agama malu-malu dan evolusif selama tidak dipaksa untuk menetapkan sesuatu kebenaran tertentu, maka agama akan diam saja. Karena itulah belakangan ini ketika seks disimpangkan yang konon seks adalah suci, tetapi telah menjadi pameran pelampiasan nafsu birahi sehingga masyarakat telah lama berpandangan bahwa pelampiasan-pelampiasan nafsu birahi adalah hal yang natural atau alami. Akhirnya pandangan yang sangat duniawi itu mengakibatkan lahirnya kejahatankejahatan seksual yang menjadi problem masyarakat. Melalui kejahatan-kejahatan seksual itu lalu semua orang berpaling kembali kepada noma-norma agama.

\subsection{Teologi Hindu Dalam Teks Rahasya Sanggama}

Secara teologis aktivitas seksual adalah aktivitas Tuhan sendiri, karena Tuhan lah yang menciptakan pasangan pria dan wanita serta menciptakan alat kelamin yang masing-masing berbeda antara keduanya. Tuhan membuatkan alat kelamin yang amat sangat sempurna pada keduanya sehingga keduanya merasakan masuk kedalam Tuhan ketika menggunakan alat kelamiannya.

Pada aktivitas untuk merasakan masuk ke dalam alam Tuhan ritual aktivitas hubungan suami istri menjadi aktivitas kedewataan. Para bijak Hindu menggambarkan aktivitas seksual pada diri Tuhan itu sendiri dituangkan dalam konsep gambaran Ardhanareswari, Imaginasi spiritual dalam bentuk Manusia Dewa yang tubuhnya setengah pria (Shiva) dan setengah wanita (Parvati) dalam satu tubuh. Dewa Shiva adalah gambaran sifat maskulinum Tuhan dan Dewi Parvati adalah simbol sifat feminim Tuhan sebagai satu kesatuan dalam diriNya. Kemudian untuk lebih mudah para awam membayangkannya sifat Tuhan yang maskulin dan feminism itu, maka para bijak membuatkan gambaran yang keduanya yaitu antara Dewa dan Dewi. 
Ajaran Weda juga menggambarkan betapa seks, cinta dan perkawinan merupakan persembahan dan laki-laki yang tidak menikah disebut sebagai orang yang tanpa persembahan. Kendati Hinduisme tidak menafikan anjuran selibat bagi para pertapa, namun hal itu tidak harus dilakukan seumur hidup, yang berarti boleh menikah, baik dari kalangan pendeta maupun orang awam. Sperma yang diyakini memiliki kekuatan magis dan vitalitas laki-laki harus dijaga dan karenanya seperti pada kebanyakan masyarakat yang patriarkis dominasi seksual terletak pada kekuatan laki-laki, karena ia tidak hanya dimaknai semata-mata kontak fisik namun juga mengandung nilai ritual keagamaan yang mempersiapkan jalan bagi perkembangan lebih lanjut yang dieknal dengan sebutan Tantra. Adanya pandangan sakramental pada seks, maka penyatuan fisik laki-laki dan perempuan diyakini sebagai tempat Pencipta meneruskan karya kemanusiaannya. Perempuan juga tidak diberi kebebasan sebenarnya, ketika kanak-kanak berada di bawah kendali ayahnya, ketika menikah dikendalikan suaminya dan ketika renta diatur anak-anaknya. Aturan Hinduisme tentang seksual agak rigid, terutama terkait dengan bagaimana seks yang benar, yakni larangan oral, perzinaan dan terutama dengan perempuan dari kelas/kasta di bawahnya.

Para bijak Hindu juga menjelaskan bahwa para dewa bukan saja mengajarkan cara berkeluarga yang baik hanya dalam angan-angan saja. Tetapi dewa dan dewi turun ke dunia untuk memberi pelajaran nyata tentang bagaimana hidup berkeluarga yang penuh dengan kasih sayang. Rama dan Sita demikian juga Krishna dan Radha adalah contoh pengejawatahan dari praktik cinta yang ditunjukkan oleh figur dewa yang turun membawakan teladan cinta. Sebagaimana telah disinggung sedikit pada bagian konsep bahwa Teologi Seksual dalam Hindu adalah seks yang dilihat dari teks teologi Hindu yang diajarkan dalam susastra Hindu seperti Manawadharmasastra, Kamasutra, Rukmini Tatwa, Arjuna Wiwaha dan lain-lain.

Bayi dalam kandungan dapat terwujud karena pertemuan antara kama petak dan kama bang, atau pertemuan antara cukla yang keluar dari purusa (laki-laki) dan swanita yang keluar dari pradana (wanita). Kama petak adalah air mani laki-laki yang juga disebut cukla, disimbulkan dengan Sang Hyang Semara dan kama bang adalah air mani perempuan yang disebut swanita, yang disimbulkan dengan Dewi Ratih. Kama petak dan kama bang ini setelah bersatu disebut 'cuklaswanita', yang disimbulkan dengan Sang Hyang Semara Ratih yang nantinya akan bertumbuh menjadi bayi di dalam kandungan. Pustaka suci Rg Veda, Mandala 10, Sukta 5, sloka 3 menyatakan:

\section{Ritāyini māyini sàm dadhāte mithvā isum jajnatur vardhayanti Visvasya nabhim càrato dhruvāsya kaves cit tantum manasa viyàntah.}

Pasangan suci itu dengan kekuatan yang mengagumkan menjadi satu pasang; mereka membentuk bayi, mereka yang memelihara melahirkan dia, titik pusat dari segala yang bergerak dan yang diam, pada saat mereka menganyam benang, Pendeta membaca mantra dengan hati-hati.

Pertemuan ini dibenarkan secara agama, apabila dilakukan oleh pasangan suami istri yang sah (Kusuma, 2012). Pertemuan cukla dan swanita atau sperma 
dan ovum dari suami istri yang diwujudkan dengan melakukan hubungan senggama mengakibatkan terjadinya pembuahan. Pertemuan antara cukla swanita ini akan menghasilkan manik, selain mendapatkan kepuasan maksimal, manik tersebut akan menjadi cikal bakal yang akan menjadi bayi. Dewasa ini dunia agama-agama mulai terbuka menerima seks sebagai wacana keniscayaan (natural) atau alamiah, namun tetap tema-tema teologi seks masih mengusik sebagian pikiran religius sehingga para akademisi yang berkutat di bidang teologi membutuhkan deskripsi yang logis kritis teologis. Melakukan sanggama dipandang sebagai penghalang bagi manusia untuk meniti jalan spiritual sehingga perdebatan pun sering terjadi ketika berbicara tentang hal itu. Banyak orang masih melakukan penghakiman dalam urusan seksualitas. Sementara hubungan seksual sesungguhnya adalah kebutuhan mendasar manusia. Kepuasan pasangan yang melakukan hubungan badan atau sanggama, hal ini tidak bisa lepas dari kontribusi tuhan itu sendiri seperti yang dikutip dalam teks Rahasya Sanggama sebagai berikut:

ngolah muwah maring tungtunging mutra wiwara, muwang sikara pasta ing jro, Om indra ya namah swaha, Om wesnawa ya namah swaha, Om apsari ya namah, Ai (Airsanya), Om ume ya namah, Pur (purwa), Om sitaye namah, Air ( Airsania); Om Arjuna ya namah, da (daksina), Om iswara ya namah, ne (neriti), Om Rudra jaye sangara ya namah, Ma (madia), yawat adres wijilnya ikang ratih, kumeter malit ikang mantra, kumeter mayuk wang kuwangnya, ri stri kaduning nari kabeg, teka yewa.

Lagi ditekan-tekan jangan terlalu keras pakai mantra ketika menekan itu, ya selama orang makan sirih (kira-kira 10 menit) di sana harus digerak-gerakan juga, lagi mantra, setelah dimasukan sekali, si laki harus menggerakan,si wanita juga harus bergerak, lagi bila diperlukan, lagi dibawa ke ujung kemaluan itu, disana tempat mengoyangkan. Membuat putra laki laki, gunakan cara dan mantram yang lain. Lamanya selama kita memasak beras hingga menjadi nasi, diulang-ulang itu, ujung-ujungnya begtu pula ujung kemaluan laki -laki yang ada di dalam, pakai mantra : Sang Hyang Indra berikanlah saya ...(ucapkan permohonan sipemohon); Sang HyangWesnawe berikanlah saya... (ucapkan permohonan sipemohon), Sang Hyang Apsari yang beradadi timurlaut, berikanlah saya ... ; Sang Hyang Uma yang berrada di timur berikanlah saya..;, Sang Hyang Sitaye yang berada di timurlaut berikanlah saya...;, Sang Hyang Arjuna yang ada di selatan berikanlah saya..; Sang Hyang Iswara yang berada di barat daya berikanlah saya..; Sang Hyang Rudra yang berada di tengah berikanlah saya.

Asta dewata disini menjelaskan bahwa dalam berhubungan seksual guna mendapatkan sesuatu yang dicapai baik itu kepuasan yang maksimal, keturunan dan moksa. Berkat dan kenikmatan yang didapat dalam berhubungan adalah dengan cara memohon kepada dewa dari segala penjuru mata angin akan membuat sanggama itu menjadi sanggama yang berkualitas dan memperoleh kesempurnaan dalam hidup/moksa. Dalam berhubungan seksual tidak hanya perlu memuaskan suatu indria belaka akan tetapi perlu juga kontribusi dari tuhan itu sendiri, pelafalan mantra sangat perlu diaplikassikan dalam berhubungan badan guna memperoleh kenikmatan material dan spiritual. 
Umat Hindu percaya bahwa kehidupan ini diliputi dan diserapi oleh mantra. Semua makhluk yang ada di dunia ini diatur oleh mantra Adapun arti dan makna sebuah mantra adalah untuk mengembangkan kekuatan supra pada diri manusia. Pikiran yang luar biasa dapat muncul dari kelahiraan, obat-obatan, mantra-mantra, pertapaan, dan kontemplasi kedewataan Berdasarkan hal tersebut, maka mantra dapat disebut sebagai suatu ucapan yang luar biasa yang dapat mengikat pikiran (Suryawan 2007:60). Dalam teks Rahasya Sanggama terdapat beberapa mantra mulai dari awal berhubungan hingga sampai tahap puncak/orgasme sebagai berikut.

(1) Mantra pembersihan diri sebelum melakukan hubungan seks

Nihan ta dening apurwa sewa ring Bhatari: Masiwikarasika kramanya nihan: Kramanya nihan Om asta desaya namah Ring wunwunan: Om king king kong kah Ring muka: Om ming mang mang mang mah Ring bawu-bawu: Om dang ding dong dang dah namah Ring dada : Om wang wing wing wong wang wah Ring nabi: Om yang yang ying ying yong yah Ring suku nga .. tarjini: Om kamabiseka ya namah...... Om kama dipati pataye namah, Om pratistaye namah, anamika, Om kusumayuda ya namah, Om pratista ya namah, tarjini. Telas nika mayoga, umarepa ta kita wetan, Lor kunang, Dyayi ta kita saprahara, Idep nikang rat nirawarana,

Beginilah caranya orang meladeni Bhatari (si istri) Harus membersihkan tangan dulu, begini caranya: pakai mantra: Ya Tuhan, kedelapan penjuru dunia, Pada ubun-ubun: (aksara yang harus diucapkan untuk bersihkan ubun-ubun), Pada muka: (aksara yang harus diucapkan) Pada pundak: (aksara yang harus diucapkan untuk membersihkan pundak), Pada dada: (aksara yang harus diucapkan untuk membersihkan dada), Pada pusar: (aksara yang harus diucapkan untuk membersihkan pusar), Pada kaki...... kelingking (sebagian aksara hilang) Ya Tuhan, semoga Engkau menganugrahi sperma yang sempurna, Dewanya Asmara, engkaulah bemama Sanghyang Pataye, Ya Tuhan, beliaulah bertempat tinggal di sana, Jari manis tangan kanan, Ya Tuhan, yang bernama Kusumayuda Engkaulah yang berada di sana, di klingking, Setelah mengucapkan semua mantra itu, menghadap ke timur engkau, Kalau tidak menghadap ke timur, bisa juga menghadap ke utara, Beryogalah engkau sebentar, Bayangkan dunia ini tidak ada nodanya

(2) Mantra ketika memegang kemaluan istri

Om gapa taye namah swaha

Ya Tuhan apa yang saya pegang semoga membawa kepuasan

(3) Mantra ketika menekan kemaluan istri:

Om arah-arahi ri hiri, ger

Ya Tuhan, apa yang saya tekan semoga membawa kepuasan. 
(4) Mantra ketika ujung penis si laki telah ada di dalam vagina:

Om indra ya nama swaha,

Om wesnawe namah swaha,

Om apsari yar yar namah, ai, (airsania)

Om ume ya namah, pur, (purwa)

Om sitaye namah, air: (airsania)

Om arjuna ya namah, da.. (daksina)

Om iswara ye namah, ne: (neriti)

Om rudra jaye sangara ya namah; ma (madia)

Sang Hyang Indra berikanlah saya (pemohonan saya)

Sang Hyang Wesnawe berikanlah saya (permohonan saya)

Sang Hyang Apsari, yang ada di timur laut, berikanlah saya

Sang Hyang Uma, yang ada di timur, berikanlah saya,

Sang Hyang Sitaye, yang ada di timur laut, berikanlah saya

Sang Hyang Arjuna, yang ada di selatan, berikanlah saya,

Sang Hyang Iswara, yang ada di Barat Daya, berikanlah saya,

Sang Hyang Rudra, yang ada di tengah, berikanlah saya.

(5) Mantra agar si wanita benar-benar merasakan kenikmatan

Om ka Ang Ah, sangke pusuh mareng wunwunan.

Secara bebas mantra ini dapat diartikan bahwa kenikmatan seks itu agar tembus dari jantung sampai ke ubun-ubun. Mantra ini digunakan agar si istri/wanita merasakan betapa nikmatnya melakukan sanggama dengan si laki/suami

Seks yang disertai dengan suatu mantra yang tergolong kedalam ajaran kama tattwa secara umum dan secara khususnya dalam penelitian ini adalah teks rahasya sanggama akan memberikan efek yang begitu besar dalam kehidupan sanggama dalam masyarakat yang melakoninya, baik itu memperoleh kepuasan, keturunan dan kesehatan jasmani maupun rohani. Mantra digunakan sudah dari zaman epos besar. Berbagai kisah dalam ceritra Mahabharata, Ramayana, dan aneka epos besar lainnya se|alu menyelipkan secara nyata hubungan antara nafsu, seks, dan dampaknya terhadap kehidupan. Para dewa pun diilustrasikan terlibat di dalamnya Misalnya, bagaimana kelahiran Raja Angga Karna yang memiliki nama panggilan Radheya dalam epos Mahabharata diilustrasikan sebagai hasil uji coba Dewi Kunti atas keampuhan mantra anugrah Rsi Durvasa, hingga tanpa sengaja ia telah memanggil Dewa Surya untuk "membuahinya".

Begitu pula kehadiran berbagai_figur utama pemegang lakon Mahabharata (Yudistira, Bima, Arjuna., Nakula, dan Sahadewa) disebutkan sebagai keturunan dari masing-masing dewa, berkat keampuhan mantra yang diucapkan Dewi Kunti dan Dewi Madri. Pengucapan sebuah mantra memang harus benar-benar akurat karena apabila pengucapan mantra tidak sesuai dengan kaidah yang berlaku atau tidak berdasarkan kitab acuan, teks lontar maka hasilnya bisa berbanding terbalik dari apa yang diinginkan. Kepuasan hubungan seksual dalam suatu perkawinan 
dapat diperoleh bila diantara keduanya terdapat komunikasi yang mendalam dan terbuka mengenai kebutuhan seksual mereka.

Apa dan bagaimana yang seharusnya dilakukan oleh pasangan suami istri agar nantinya kebutuhan seksual mereka dapat terpenuhi dan dapat memuaskan kedua belah pihak, sehingga terjadi komunikasi pasangan suami istri tesebut, akhirnya dapat mengetahui keinginan dan kebutuhan masing-masing. Berdasarkan uraian pandangan masyarakat umum dan pandangan para pakar seks masih melihat sebagai persoalan kepuasan seks belum melihat seks sebagai satu kewajiban suci apalagi sebagai persembahan. Pandangan umum itu muncul akibat adanya berbagai kasus criminal atau kejahatan-kejahatan seks yang semakin meningkat kuantitas dan kualitasnya. Itulah hakikat Teologi Seksual bertujuan agar manusia hidup bahagia baik dalam keadaan suka maupun duka. Hubungan seksual suami istri dapat menambah ketahanan keluarga menghadapi suka dan duka. Seks dan agama diyakini sebagai dua entitas yang menempati ruang yang berbeda. Seks diasumsikan bersifat fisis dan agama berdimensi spiritual, padahal keduanya sesungguhnya sama sekali tidak berada di luar eksistensi manusia. Anak manusia terlahir juga karena peristiwa seksual. Ia bertahan, berkembang dan lestari karena peristiwa tersebut. Namun, manusia tidak cukup hanya dengan kebutuhan fisikbiologis ini, ia juga membutuhkan "makanan" spiritual yang lazim didapatkan dari agama. namun, karena seks bukanlah sesuatu yang sama sekali lain dari agama, maka teks-teks keagamaan tentang seks juga inhern dengan eksistensi agama itu sendiri. Agama yang diturunkan untuk manusia, tentu juga mengatur dimensidimensi kemanusiaan, termasuk seks yang menjadi salah satu dimensi kemanusiaan yang naturalistik.

\section{SIMPULAN}

Seks semestinya telah diberikan kepada para remaja ketika mereka mulai memasuki masa akil balig (menek kelih), sebab mulai saat ini kekuatan Kama Ratih mulai berkembang dalam diri manusia. Seks bukan hanya sekedar pemuas nafsu akan tetapi melahirkan keturunan yang suputra merupakan hal yang perlu diketahui oleh masyarakat. Diketahui bahwa unsur laki-laki dan wanita memiliki beberapa macam sebutan: 1. Unsur laki-laki disebut kama petak, sukla, kamajaya, Sang Hyang Semara, sperma, sel mani, air mani.

Kepuasan pasangan yang melakukan hubungan badan atau sanggama, hal ini tidak bisa lepas dari kontribusi tuhan itu sendiri. Berkat dan kenikmatan yang didapat dalam berhubungan adalah dengan cara memohon kepada dewa dari segala penjuru mata angin akan membuat sanggama itu menjadi sanggama yang berkualitas dan memperoleh kesempurnaan dalam hidup/moksa. Seks yang disertai dengan suatu mantra yang tergolong kedalam ajaran kama tattwa secara umum dan secara khususnya dalam penelitian ini adalah teks rahasya sanggama akan memberikan efek yang begitu besar dalam kehidupan sanggama dalam masyarakat yang melakoninya, baik itu memperoleh kepuasan, keturunan dan kesehatan jasmani maupun rohani.

Lontar Rahasya Sanggama ini mendidik umat yang telah membaca ajaran yang terkandung didalamnya agar tidak disebarluaskan ke sembarang orang, mantra-mantra/doa-doa yang tersirat dalam lontar ini hanya bisa dipelajari dan diaplikasikan oleh orang yang sudah sah dalam berumah tangga atau dalam Agama Hindu sah dalam upacara keagamaan dalam sekala maupun niskala. Seksualitas dan 
spiritualitas merupakan dimensi yang penting dan terpadu, dimana melalui seksualitas manusia, individu dapat mengalami hubungan erotis langsung dengan Tuhan. Ajaran lontar Teks Rahasya Sanggama menerangkan bahwa dalam kegiatan bersenggama terdapat nilai-nilai spiritualitas yang sangat mendasar dalam Melakukan hubungan seks yang sah dan sakral, dianjurkan agar hubungan yang melampui badan. Artinya, hubungan badan tersebut memiliki dua tugas pokok, yaitu melanjutkan keturunan yang berkualitas dan mencapai kenikmatan yang magis.

\section{DAFTAR PUSTAKA}

Agung, Jaya Suryawan I.G. 2007. Ajaran Seksualitas Dalam Lontar Rahasya Sanggama: Kajian Bentuk, Fungsi, dan Makna. Tesis Institut Hindu DharmaNegeri Denpasar. Tidak diterbitkan

Anindyajati, G. (2014, Juli 14). Seks, seksual, dan seksualitas. Retrieved Agustus 21, 2017, from angsamerah.com: http://blog.angsamerah.com/seks- seksualdan-seksualitas/

Aryana, IB. Putra M, 2006.Seks Ala Bali Menyibak Tabir Rahasya Sanggama Tattwa. Denpasar: Bali Aga.

Gulo, W. 2004. Metodologi Penelitian. Jakarta: PT. Gramedia Widiasastra Indonesia.

Hartoko dkk. 1992. Manusia dan Seni. Yogyakarta: Kanisius

Huguelet, P., Mohr, S., Borras, L., Gillieron, C., \& Brandt, P.-Y., 2006. Spirituality and religious practices among outpatients with schizophrenia and their clinicians. Psychiatric Services, 57(3), 366-372.

Jacobi, J. (1973). The Psychology of C.G. Jung. Michigan: Yale University Press.

Rosidi. (2010). Spiritualitas dan Konsep Diri Narapidana (Studi Narapidana LP Kedungpane). Laporan Penelitian Individu, IAIN Walisongo Semarang.

Mappiare, Andi. 1982. Psikologi Remaja. Surabaya: Usaha Nasional.

Maswinara, I Wayan. 1997. Kamasutra : Asli Dari Watsyayana. Surabaya: Paramita.

Narbuko . Cholid.2003. Metodelogi Penelitian.Jakarta Bumi Aksara.

Offman, A., \& Matheson, K. (2005). Sexual compatibility and sexual functioning in intimate relationships. Canadian Journal of Human Sexuality, 14(1/2), 31.

Paririnder, Geoffrey. 2005. Teologi Seksual. Penerjemah Amirudin dan Asyhabuddin. Editor Rahmat Widada. Yogyakarta: Lkis Yogyakarta.

Pujda. G, M.A. dan Tjokorda Rai Sudharta.2004. Manava Dharmasastra. Surabaya: Paramita.

Suwantana, I Gede. 2011. Seks Sebagai Pendakian Spiritual: Kajian Teks Resi Sambina.Denpasar: Pustaka Bali Post.

Swastika, I Ketut. 2010. Grhastha Asrama: Menuju Keluarga Satyam-SivamSundaram Surabaya: Paramita. 
Teeuw, A. 1984. Sastra dan Ilmu Sastra. Bandung: PT. Kiblat Buku Utama.

Tim. 1991. Kamus Besar Bahasa Indonesia. Jakarta: Depdikbud.

Tim Penyusun. 1999. Siwa Tattwa. Denpasar: Upada Sastra.

Titib, I Made. 1996. Manawa Dharma Sastra. Surabaya: Paramita.

Underwood, L.G.Teresi, J.A. (2002). The daily spiritual experience scale: Development, theoretical description, reliability, exploratory factor analysis, and preliminary construct validityusing health-related data. The Society of Behavioral Medicine, 24 (1), 22-33. Hebrew Home for the Aged at Riverdale and Columbia University StroudCenter.

Underwood, L.G. (2011). The daily spiritual experiencescale: Overview and result. Religions, 2, 29-50. DOI:10.3390/rel2010029.

Utama, I Wayan Budi. 2004. Seksualitas dalam Brahma Widya (Teologi) dan Tradisi Hindu di Bali. Tesis Universitas Hindu Indonesia Denpasar. Tidak diterbitkan 